\title{
Erratum to: Nonradiographic axial spondyloarthritis. What brings the new concept?
}

\author{
E. Collantes-Estevez $\cdot$ Luis R. Espinoza
}

Published online: 19 December 2014

(C) International League of Associations for Rheumatology (ILAR) 2014

\section{Erratum to: Clin Rheumatol}

DOI 10.1007/s10067-014-2805-x

The original version of this article unfortunately contains an error in the name of one of the authors. The name Luis R. Espinosa should be Luis R. Espinoza. The correct presentation of author name is presented above and in the affiliation section.

The online version of the original article can be found at http://dx.doi.org/ 10.1007/s10067-014-2805-x.

E. Collantes-Estevez $(\bowtie)$

Rheumatology Department "Reina Sofia" Hospital, Maimónides Institut for Biomedical Research of Córdoba (IMIBIC)/University of

Córdoba, Córdoba, Spain

e-mail: educollantes@yahoo.es

L. R. Espinoza

Section of Rheumatology, LSU Health Sciences Center, New

Orleans, USA 